\title{
Patient Reported Outcomes of Infusional Prostaglandin E1 in Peripheral Arterial Disease
}

\author{
Toney Jose ${ }^{1 *}$, Arya Joy ${ }^{1}$ and John Sajan Kurien ${ }^{2}$ \\ ${ }^{1}$ Resident, Department of General Surgery, Govt Medical College Kottayam, India
}

${ }^{2}$ Professor, Department of General Surgery, Govt Medical College Kottayam, India

Submission: December 08, 2017; Published: December 20, 2017

*Corresponding author: Toney Jose, Resident, Department of General Surgery, Govt Medical College Kottayam, India, Email: toneyonly@gmail.com

\begin{abstract}
The use of prostaglandin E1 in peripheral occlusive arterial disease is an option for patients for who interventional options are not present This study assessed the patient reported outcomes and perception of benefits of infusion therapy. 30 patients who completed their 5th month of infusional therapy were included in the study. 3 patients had major lower extremity amputations, 13 had minor lower extremity amputations during the course of infusion therapy. The mean visual analogue scale score prior to treatment was 8.5 prior to treatment and the VAS score was 6.2 post infusion. All patients were satisfied to continue their treatment with PGE1 and perceived a benefit from the therapy. Thus infusional PGE1 is a therapeutic option for patients in whom revasularisation options are not available.
\end{abstract}

Keywords: Prostaglandin E1; Peripheral vascular disease; Outcome

\section{Introduction}

Peripheral occlusive vascular disease is one of the common ailments causing significant morbidity mainly in the elderly population. With the changing demographic pattern of diseases, patients with non communicable diseases like peripheral arterial diseases are increasing in number. The changing life style, high calorie diet, lack of exercise has resulted in a phenotype of poor vascular pathological anatomy and resulted complication in the cardiovascular, cerebrovascular and peripheral vascular systems.

While the therapies for obstructive pathologies in cardiovascular and cerebrovascular systems were extensively studied, the progress in the management of obstructive pathologies in peripheral vascular system received impetus only lately. Surgical and endoluminal therapies that are numerous target large and medium sized vessels. The small vessels of the extremities lack in number of therapeutic options. While endoluminal procedures have been attempted for small vessels, their success rates are dismal. This necessitates the use of medical management in treating such lesions which are not amenable to surgical and endoluminal intervention. Use of prostaglandin E1 in the treatment of patients with limb threatening ischemia has long been tried [1]. The present study was done to evaluate the benefits of infusional prostaglandin E1 from the patient point of view.

\section{Methods}

This cross sectional observational study was carried out in the Department of General Surgery of our Institute after getting ethical clearance. The infusion therapy of prostaglandin E1 as followed in the Department was infusion at the rate of $10 \mathrm{mcg}$ per hour for 10 hours for 5 consecutive days. This is repeated every month for 6 months. Patients undergoing treatment for their peripheral vascular disease with prostaglandin E1 infusion were included in the study. Only patients who completed their 5th months of infusion were included in the study. Patients were included with informed consent. Patients with cognitive impairment were excluded from the study. Patients who had major lower extremity amputations prior to start of infusion therapy were excluded from study. The patients were asked to chart their pain on the visual analogue scale and to compare with the pain prior to start of therapy. They were also asked to comment on their satisfaction with therapy as satisfactory, moderately satisfactory and poor. They patients were also asked whether they would have opted for this treatment mode if given a second chance. The patients were asked to give a score for the satisfaction with therapy from 0 to 10 . Data was collected and analysed using Microsoft Excel and SPSS. 
Results

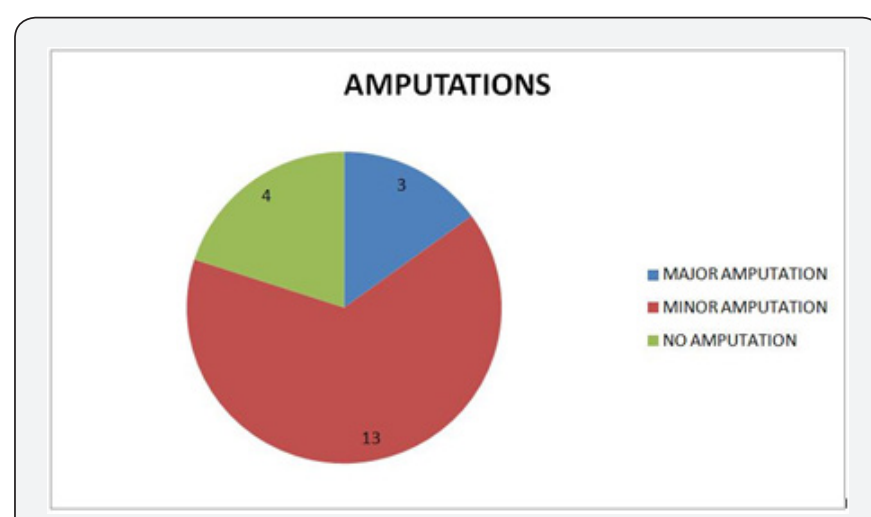

Figure 1: Amputations underwent by patients.

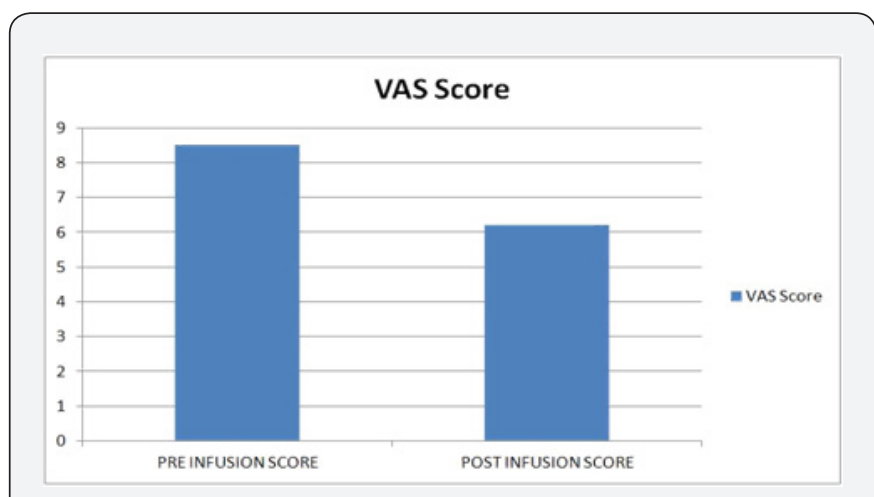

Figure 2: Visual analogue score before and after infusion therapy.

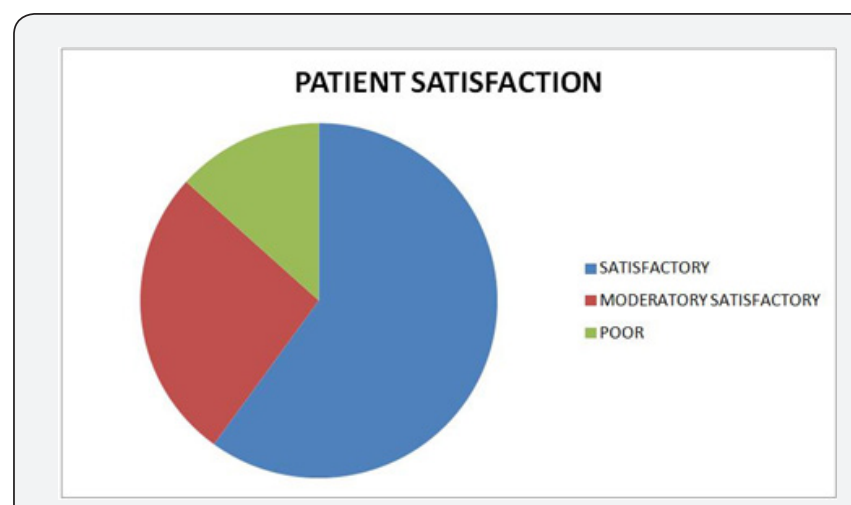

Figure 3: Patient reported satisfaction for prostaglandin E1 infusion

The study included 30 patients who underwent treatment with prostaglandin infusion for peripheral vascular disease. All patients included had atherosclerotic narrowing precluding vascular intervention as etiology of their vascular disease. Mean age was 76 (range 55 to 80). 18 were in Fontaine Grade III and 12 were grade IV before their infusion therapy began. 3 patients had major lower extremity amputations, 13 had minor lower extremity amputations during the course of infusion therapy (Figure 1). All the patients had rest pain prior to start of the infusion therapy. 9 patients reported the absence of rest pain at interview at 5 months. The mean visual analogue scale score prior to treatment was 8.5 prior to treatment and the VAS score was 6.2 post infusion $(\mathrm{p}<0.05)$ (Figure 2). The patient satisfaction assessment showed that 18 patients gave satisfactory, 8 moderately satisfactory and 4 gave as poor (Figure 3). When asked whether they would have opted for the therapy if given a second chance, all 30 patients responded with yes. The mean satisfaction score for therapy was 7.5 (scale was from $0-10$ ).

\section{Discussion}

Intravenously or intra-arterial infusion of PGE1 in patients with severe peripheral vascular disease has been well documented to be a safe and effective method of treatment in this group of patients who have a very limited choice of treatment [24]. PGE1 mechanisms of action include peripheral vasodilatation, improvement of microcirculation, and inhibition of platelet aggregation [5-7].

This study assessed the benefits of PGE1 infusion as noted from the patient point of view. As seen from the results, majority of patients are satisfied with the therapy. And a good portion shows improvement in their symptoms -mainly rest pain. For how long does the benefits from PGE1 infusion would last is still to be investigated.

\section{References}

1. Balzer K, Rogatti W, Tuttgerodt K (1989) Efficacy and tolerability of intra-arterial and intravenous prostaglandin E1 infusions in occlusive arterial disease stage III/IV. Vasa supplement 28: 31-38.

2. Strecker EP, Ostheim Dzerowycz W, Boos I (1998) Intraarterial infusion therapy via a subcutaneous port for limb-threatening ischemia: a pilot study. CardioVascular and Interventional Radiology 21(2): 109-115.

3. Laurora G, Corsi M, Bucci M, Cesarone MR, Belcaro G, et al. (1998) European trial of $\mathrm{PGE}_{1}$ alpha cyclodextrin: short-term versus longterm therapy in intermittent claudication. Minerva Cardioangiologica 46(10): 21-29.

4. Krawzak HW, Strosche H, Buchholz J, Jakel F (19983) Implantation technique and complications of totally implanted arterial access systems for long-term therapy in patients with occlusive vascular disease. Cardiovascular Surgery 30(6): 921-924.

5. Gruss JD, Vargas Montano H, Bartels D (1984) Use of prostaglandins in arterial occlusive disease. Inter Angio 3: 7-17.

6. De Sanctis MT, Incandela L, Iacobitti P (1998)'Responders and nonresponders' to $\mathrm{PGE}_{1}$ and alpha-cyclodextrin. Minerva Cardioangiologica 10(1): 31-36.

7. Kurien JS, Ulahannan SE, Varghese SA, Thangavel S, Darrussalah M, et al. (2017) Effectiveness of prostaglandin E1 in the pain management of patients with critical limb ischemia A prospective observational study. J Evid Based Med Health 4(67): 4011-4014. 

CC Commons Attribution 4.0 License DOI: $10.19080 /$ JOCCT.2017.08.555750
Your next submission with Juniper Publishers will reach you the below assets

- Quality Editorial service

- Swift Peer Review

- Reprints availability

- E-prints Service

- Manuscript Podcast for convenient understanding

- Global attainment for your research

- Manuscript accessibility in different formats

( Pdf, E-pub, Full Text, Audio)

- Unceasing customer service

Track the below URL for one-step submission https://juniperpublishers.com/online-submission.php 